\title{
Reference To Study Results Citation Description
}

National Cancer Institute

\section{Source}

National Cancer Institute. Reference To Study Results Citation Description. NCI

Thesaurus. Code C94042.

A bibliographical reference in a format acceptable to the registration authority. 